\title{
How visual fatigue and discomfort impact 3D-TV Quality of Experience: a comprehensive review of technological, psychophysical and psychological factors
}

\author{
Matthieu Urvoy* . Marcus Barkowsky · Patrick Le Callet
}

Received: date / Accepted: date

\begin{abstract}
The Quality of Experience (QoE) of 3D contents is usually considered to be the combination of the perceived visual quality, the perceived depth quality, and lastly the visual fatigue and comfort. When either fatigue or discomfort are induced, studies tend to show that observers prefer to experience a $2 \mathrm{D}$ version of the contents. For this reason, providing a comfortable experience is a prerequisite for observers to actually consider the depth effect as a visualization improvement.

In this paper, we propose a comprehensive review on visual fatigue and discomfort induced by the visualization of 3D stereoscopic contents, in the light of physiological and psychological processes enabling depth perception. First, we review the multitude of manifestations of visual fatigue and discomfort (near triad disorders, symptoms for discomfort), as well as means for detection and evaluation. We then discuss how, in 3D displays, ocular and cognitive conflicts with real world experience may cause fatigue and discomfort; these includes the accommodation - vergence conflict, the inadequacy between presented stimuli and observers depth of focus, and the cognitive integration of conflicting depth cues. We also discuss some limits for stereopsis that constrain our ability to perceive depth, and in particular the perception of planar and in-depth motion, the limited fusion range and various stereopsis disorders. Finally, this paper discusses how the different aspects of fatigue and discomfort apply to $3 \mathrm{D}$ technolo-
\end{abstract}

\footnotetext{
* Corresponding author

Matthieu Urvoy* . Marcus Barkowsky · Patrick Le Callet

LUNAM Université, Université de Nantes, IRCCyN UMR CNRS 6597, Institut de Recherche en Communications et Cybernétique de Nantes, Polytech Nantes, rue Christian Pauc BP 5060944306 Nantes Cedex 3

E-mail: \{matthieu.urvoy, marcus.barkowsky, patrick.lecallet\} @univ-nantes.fr
}

gies and contents. We notably highlight the need for respecting a comfort zone and avoiding camera and rendering artifacts. We also discuss the influence of visual attention, exposure duration and training. Conclusions provide guidance for best practices and future research.

Keywords Visual fatigue - visual discomfort · 3D-TV . Quality of Experience $\cdot 3 \mathrm{D}$ technologies $\cdot$ stereopsis

\section{Introduction}

Today's market for 3D imaging technologies has been growing due to the recent availability of an increasing set of contents. Various imaging technologies are available, such as volumetric or holographic systems, although stereoscopic and auto-stereoscopic systems are most commonly used [1]. The provided sensation of depth is vivid and enhances the overall user experience.

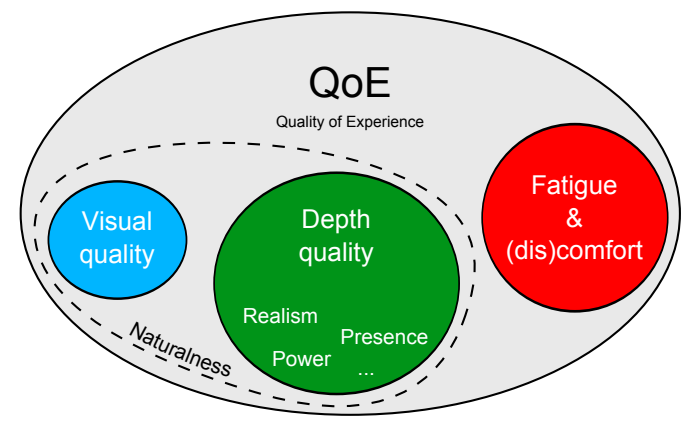

Fig. 1 3D-TV quality of experience: main features

The resulting Quality of Experience [2] has been described through various features. However, three main axis emerge [3-6] (Figure 1). Firstly, the visual quality reflects the image quality regardless of the depth effect. 
Secondly, the depth quality reflects the quality of the 3D effect and has been assessed by different features such as realism, power and presence [7]. Alternatively, naturalness is proposed as a dual feature representative of both the visual and the depth qualities [3,4]. Finally, visual fatigue and discomfort reflect the physiological and psychological demands induced by the perception of $3 \mathrm{D}$ contents.

Some studies show that observers tend to prefer a $2 \mathrm{D}$ presentation over a $3 \mathrm{D}$ presentation when either fatigue or discomfort are induced [8]. In other words, it is necessary to limit fatigue and discomfort in order for observers to actually consider the depth effect as a visualization improvement.

Reviews on human factors influencing the perception of the depth effect in 3D stereoscopic displays are available in $[9,10]$ but they do not emphasize fatigue nor discomfort. In [11], UKAI and HowARTH provide an overview of studies on ocular fatigue with stereoscopic displays from the literature, and TAM et al. an overview on visual comfort in [12]. Finally, LAmBOOIJ et al. [13] and HowARTH [14] for both visual fatigue and discomfort in the light of specific issues introduced by $3 \mathrm{D}$ technologies and contents.

In this paper, we review both visual fatigue and discomfort, first in the light of ocular and cognitive mechanisms, then in the light of 3D contents, processing and rendering, without focus on specific displaying systems. Section 2 first reviews definitions for visual fatigue and discomfort. Section 3 then reviews subjective and objective manifestations of fatigue and discomfort. Section 4 then raises different ocular and cognitive processes and dysfunctions, related to depth perception, which possibly cause reviewed manifestations. Section 5 then discusses scenarios in which 3D technologies and contents possibly generate fatigue and discomfort. Finally, section 6 concludes and provides guidance for best practices and future research with 3D stereoscopic systems.

\section{Visual fatigue and visual discomfort: existing terminologies and evaluation methods}

Depending on the scope of the studies (medical, technological, etc), terminologies for visual fatigue and discomfort vary; provided definitions can be ambiguous. For instance, terms such as fatigue, strain and asthenopia are co-existing in the literature, but their differences are unclear. In recent works [13,15], LAmBooiJ et al. did great work in providing cross-fields definitions for fatigue and discomfort. They define fatigue as a decrease in the performance of the human visual system as a consequence of physiological strain or stress resulting from excessive exertion [15]. In the same study,
LAMBOOIJ et al. defined visual discomfort as the subjective counterpart of visual fatigue, and only reflects some aspects of the Quality of Experience (QoE).

Adaptation mechanisms from the visual system are sometimes known to improve its performances, yet the adaptation itself may as well induce fatigue $[15,16]$ : both decreases and increases in performances of the visual system may be related to visual fatigue. As for visual discomfort, it is perceived instantaneously, while fatigue is induced after a given duration of effort. Finally, how fatigue relates to discomfort is still an open question [15]. These observations show the need for further efforts in defining visual fatigue and discomfort, to notably account for both worsening and improving effects, as well as temporal aspects.

Typically, questionnaires are used to assess the presence of symptoms for fatigue and discomfort. In [17], KENNEDY proposed a questionnaire assessing simulator sickness (SS). As visual fatigue, discomfort and simulator sickness share common symptoms, this questionnaire was soon adapted by HowARTH and COSTELLO for more general purposes [18]. Later studies proposed additional questionnaires [19], some of which specifically targeting ocular disorders [20]. Some studies [21] also employed the SuzumurA questionnaire, a 37 items, five stage questionnaire [22], assessing not only visual symptoms. Recent studies often mix items from the SS questionnaire [17] with more general QoE questions [23]. Discomfort, in particular, is often evaluated with subjective scales [24], such as Single Stimulus Continuous Quality Evaluation [25].

Objective tests can also be conducted in order to assess the presence of fatigue. In [15], for instance, the authors measure the tear film break-up time to determine the dryness of the eye. Experimental designs assessing visual fatigue usually follow one of two approaches: (1) following a visual task, the presence of symptoms is assessed along with the perceived degree of fatigue [24, 26]; (2) fatigue is voluntarily induced through demanding and repeated visual tasks which allows for symptoms identification [27].

\section{Subjective and objective signs of fatigue and discomfort}

Numerous studies, notably emanating from the medical research community, searched for objective and subjective signs for both fatigue and discomfort. Various effects were observed, whose majority are either ocular or cognitive. Yet, more general signs such as stiffed shoulders, modified respiratory and cardiac rhythms [28,29] and saliva cortisol concentration [29] were also related to fatigue and discomfort. 


\subsection{Ocular and oculomotor fatigue}

There is a large number of objective and subjective signs for visual fatigue [30], such as dried mucus of the eyes, tears around the eyelid, changes in blinking rate [31] and reduction of the speed of eye movements [32, 33 ] to cite only a few of them. Researchers particularly focused their efforts on the near vision triad (accommodation, vergence and pupillary response): even in $2 \mathrm{D}$ displays, numerous studies reviewed by BLEнм et al. in [34] showed that visual fatigues transiently induces accommodation and vergence disorders.

\subsubsection{Accommodation disorders}

The accommodation $(\mathbf{A})$ is the process by which the eye adapts the shape of the pupil, thus adapting its optical power to the object of interest (gaze point), in order to provide a clear image of the targeted object. Accommodation is measured in diopters $(\delta)$, the reciprocal of the accommodation distance (focus point).

The accommodation distance is biased and is generally shifted towards a resting distance called tonic accommodation or dark-focus $(\approx 1 \delta)$ : the refraction state of the eye in the absence of visual stimulus. This effect is called adaptation of the accommodation [35,36] and results in accommodation lead or lag (see Figure 2).

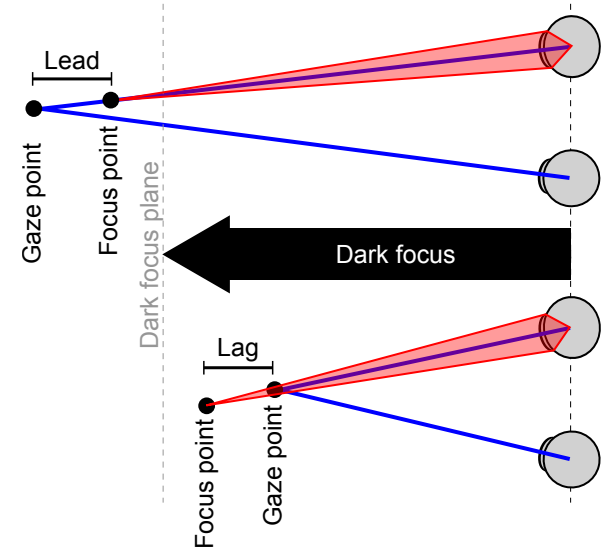

Fig. 2 Accommodation adaptation: lead (top) and lag (bottom): bias shifts the accommodation towards dark focus.

Susceptibility to visual fatigue may vary with the value of the tonic accommodation. In [37], JASCHINSKIKRUZA showed that persons whose tonic accommodation is high, thus having far dark focus, report more visual symptoms. In [38], monocular and binocular accommodation and vergence efforts were used to induce visual fatigue and resulted in a reduction of the tonic accommodation (up to $0.50 \delta$ less). This can be considered as a counter-adaptive mechanism.
Finally, visual fatigue has also been shown to influence the accommodation response. In [24,39], YANO et al. measured the accommodation response to a $5 \delta$ pulse wave before and after exposure to $2 \mathrm{D}$ and $3 \mathrm{D}$ stereoscopic video sequences. Reported subjective scores for the perceived fatigue correlate to a reduction of the accommodation amplitude; this reduction is larger in $3 \mathrm{D}$ $(>0,5 \delta)$ than in $2 \mathrm{D}(<0,5 \delta)$. Similar results were obtained by Uetake, Murata et al. after exposure to $2 \mathrm{D}$ contents in $[40,41]$.

\subsubsection{Vergence disorders}

(Con)vergence $(\mathbf{C})$ is the process by which both eyes simultaneously move in opposite directions (convergence or divergence movements), so that a targeted object appears at the center of both retinas. Vergence is measured in prism diopters $\left(\delta_{\Delta}\right)$. Like in accommodation, the vergence point is generally shifted towards its resting position, called phoria or dark vergence [42]. The resulting vergence error is called fixation disparity (or reciprocally stability) $[43,44]$. This phenomenon is referred to as vergence (or prism) adaptation.

Several studies link vergence adaptation disorders to visual fatigue. In [45], JASCHINSKI-KRUZA showed that fatigue increases at near vision $(50 \mathrm{~cm})$ with the distance between the vergence point and the distance of dark vergence. In [46], he also showed that fatigue also increases with the slope of the curve that relates the viewing distance to the fixation disparity. Other studies $[47,48]$ conducted on groups of 15 patients exhibiting asthenopic symptoms showed that most of them present a deficient adaptation to base-in (causes eye divergence) or base-out prisms (causes eye convergence). Similar results were obtained in [15]: these deficiencies may contribute to the detection of persons who are particularly susceptible to visual fatigue.

\subsubsection{Oculomotor disorders}

When a real object is perceived under binocular vision, both the focus point and the vergence point concur. The oculomotor system is specifically tuned to such a scenario and features a crosslink between accommodation and vergence: accommodation feedback may initiate vergence responses (convergence accommodation -CA-) and vice-versa (accommodative convergence AC-) [49]. It is usually evaluated through $\mathbf{C A} / \mathbf{C}$ and $\mathbf{A C} / \mathbf{A}$ ratios; $\mathbf{C A} / \mathbf{C}$, for instance, is the slope of the curve that links the amount of induced convergence accommodation from the feedback of a given amount of convergence. Fusional convergence $(\mathbf{C})$ is faster than the accommodative convergence $(\mathbf{A C})$ : the former obeys 
to retinal disparity (the retinal shift between left and right views of the same position) while the latter obeys, through accommodation feedback, to retinal blur. Conversely, convergence accommodation (CA) speeds up accommodation through convergence feedback.

This accommodation - vergence balance, also known as oculomotor balance, is influenced by visual fatigue. In [50], for instance, visual fatigue was induced by the visualization of a 2 hours 2D movie on a Head Mounted Display (HMD). Results show a significant reduction of the $\mathbf{A C} / \mathbf{A}$ ratio. In [27], a similar experiment was performed with a cross-shaped $3 \mathrm{D}$ stereoscopic stimulus moving in depth: both $\mathbf{A C} / \mathbf{A}$ and $\mathbf{C A} / \mathbf{C}$ ratios are reduced. Conversely, another study [51] involving accommodation and vergence ramp tracking exercises showed opposite evolutions of $\mathbf{A C} / \mathbf{A}$ and $\mathbf{C A} / \mathbf{C}$ ratios: the one ratio originating from the targeted mechanism (accommodation or vergence) increased, while the other ratio decreased. The modification of the oculomotor balance can thus be interpreted as the result of adaptation processes that allow for conflicting demands in accommodation and vergence to be resolved more efficiently.

\subsubsection{Pupillary disorders}

Third element of the near triad, the pupil size and its changes are affected by visual fatigue as well. In [52], for instance, NAKAMURA showed that pupillary disorders were more frequent amongst a group of patients suffering from asthenopia than in a group of unaffected patients. In $[40,41]$, the perceived fatigue reported by the observers, after visualization of 60 minutes of $2 \mathrm{D}$ video sequences, correlated with a reduction of the pupil diameter. In [53], UKAI et al. showed that in $30 \%$ of cases, patients experiencing visual fatigue presented an abnormal exaggeration of the rhythmic contraction (myosis) and dilation (mydriasis) of the pupil, independent of changes in illumination or in fixation of the eyes, called hippus [54]. Finally, a study [28] showed that the pupillary light reflex is less controlled in a group of patients suffering from mild autonomous dysfunctions.

\subsection{Cognitive fatigue}

While visual fatigue manifests itself through ocular disorders, it also induces cerebral and psychological disorders such as headaches [28]. What is more, studies notably showed that the visualization of $3 \mathrm{D}$ stereoscopic sequences may further delay event-related potentials (ERPs) such as P100 (at $100 \mathrm{~ms}$ ) [28] and P700 (at $700 \mathrm{~ms}$ ) [55]. These observations tend to demonstrate that visual fatigue also affects cognitive processes from the human visual system (HVS). More specifically, cognitive fatigue with $3 \mathrm{D}$ stereoscopic stimuli may affect stereopsis, the process by which left and right views are fused into a single percept featuring depth information. The performance of the binocular fusion is usually assessed by the fusion range: the interval of retinal disparities for which it is possible to fuse left and right retinal images.

In [15], LAMBOoIJ et al. correlated short term visual fatigue, induced by the reading of a $3 \mathrm{D}$ stereoscopic text (Wilkins test), to an increase of the fusion range. Inversely, several studies correlated long term fatigue, induced by the visualization of 60 minutes of $3 \mathrm{D}$ stereoscopic stimuli, to a reduction of the fusion range [56-58]; baseline fusion range was restored after 5 to 10 minutes rest. Similarly to ocular deficiencies, the fusion range may be used to identify persons susceptible to visual fatigue $[59,15,60]$ : persons with small fusion range reported more visual fatigue symptoms.

There are mainly two different ways to measure the fusion range: (1) by increasing the disparity of an initial stimuli, for which fusion is possible, until diplopia (double vision) appears; inversely, (2) by decreasing the disparity of an initial stimuli, whose disparity falls outside of the fusion range, until fusion is achieved. Both methods provide different fusion limits, giving rise to a fusion hysteresis, which in turn may be used to detect visual fatigue [56].

Some studies considered alternative characteristics of the binocular fusion. In [57], for instance, Емото et al. used the occurrences of diplopia episodes. Stereoscopic acuity (one person's acuity at depth perception) $[61,51]$ and fusion speed [61] were correlated to visual fatigue as well.

\subsection{Signs for discomfort}

Discomfort being subjective by definition, almost all studies evaluating discomfort rely on questionnaires [17$21,23]$, whose aim is to assess the presence of numerous symptoms specific to discomfort. Most studies, however, require for observers to rate the level of discomfort on a scale.

Amongst the large set of assessed symptoms, some of them proved to be particularly significative: ocular pain and irritation $[62,15,63]$, double vision $[15,64]$, blurry vision $[15,64]$ and focusing difficulty $[62,63]$, nausea [62] and headache [62].

More recently, some studies correlated discomfort to objective measurements. In [63], KIM et al. correlated the discomfort, perceived during the visualization of a $3 \mathrm{D}$ stereoscopic stimulus, to the level of cortical activity 
of the frontal eye field. This cortical area plays an important role in controlling the eye movements. In [65], Li et al. showed that the eye blinking rate was inversely proportional to the discomfort level when visualizing a static 3D stereoscopic stimuli, and conversely, proportional to the discomfort level when visualizing stimuli moving in a plane parallel to the screen plane.

\section{Causes of fatigue and discomfort}

Previous sections reviewed various effects of fatigue and discomfort. This section will now discuss different issues, specific to 3D perception, that are considered as potential sources of fatigue and discomfort.

\subsection{Ocular constraints}

\subsubsection{Accommodation - vergence conflict}

With (auto)stereoscopic displays, vergence point and focus point are not synchronized anymore. Indeed, the observer needs to accommodate on the screen, hence at the viewing distance. At the same time, any object with crossed disparity (left and right views are respectively shifted towards right and left) or uncrossed disparity (left and right views are respectively shifted towards left and right) will require the same observer to converge at a point which is located in front of or behind the display plane. This is illustrated in Figure 3. Uncorrelated demands in vergence and accommodation thus conflict with their oculomotor coupling.

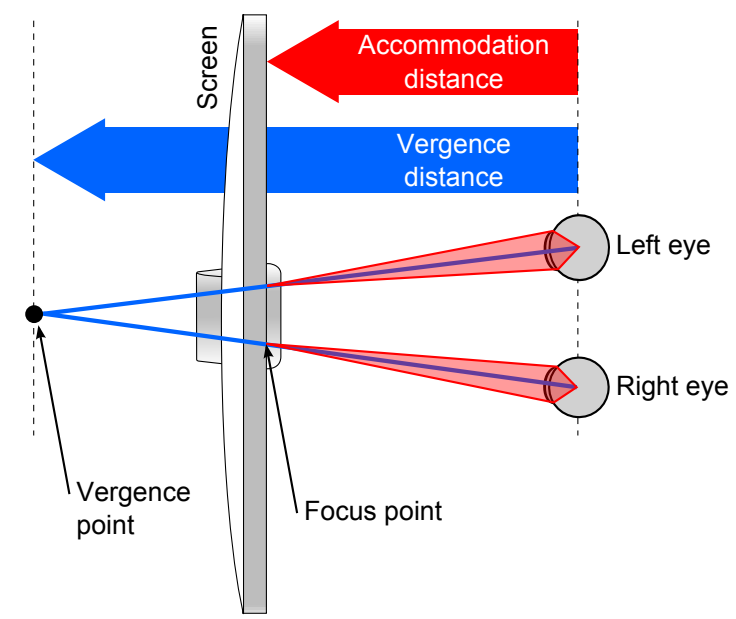

Fig. 3 Accommodation - vergence conflict: the observer eyes accommodate on the screen plane and convergence at the imaged depth.

A significant number of studies proposed that the accommodation - vergence conflict induces an instable behavior of the oculomotor system which keeps oscillating between demands in accommodation and vergence. Yet, the accommodation lead or lag renders it difficult to verify such an hypothesis. In [66], for instance, INOUE and OHzU showed that accommodation, in the presence of a conflicting vergence demand, exhibited unusual behavior. In [67], the presentation of large screen disparities (up to $2.6^{\circ}$ of visual angle) resulted in convergence difficulties and oculomotor instabilities.

In [68], the increase of the degreee of accommodation - vergence conflict increases the role of convergence accommodation, while the role of focus accommodation diminishes with increasing amounts of retinal blur. Later studies $[69,70]$ proposed that accommodation transiently follows convergence accommodation, then rely on the retinal blur to adjust its value.

There is a general consensus that accommodation vergence conflict is an important source of visual fatigue and discomfort $[39,57,61,66,71,27,72]$. Several observations tend to support this affirmation: (1) the time required to fuse a binocular stimulus monotonically increases with increasing conflict [61,73]; (2) the stereo acuity is higher when accommodation and vergence concur $[61,74]$; (3) the degree of fatigue increases with the degree of conflict $[39,24,57,61]$. What is more, a study [58] showed that the visualization of stereoscopic images induced discomfort when the screen disparity (the horizontal shift between left and right view at the screen plane) was larger than 60 minutes of arc.

\subsubsection{Planar and in-depth movements of 3D contents}

Some researchers argued that visual fatigue and discomfort are more likely to be induced by variations in the amount of accommodation - vergence conflict, rather than by the conflict itself $[39,24,57,75]$. According to this theory, scenarios inducing repeated changes in vergence load, such as stereoscopic contents featuring in-depth motions or a large depth interval between foreground and background planes, are likely to induce fatigue and discomfort.

In [58], for instance, the visualization of 3D stereoscopic stimuli whose disparity underwent discontinuous variations larger than 60 minutes of arc induced visual discomfort. In a similar experiment [58], discomfort was induced by the visualization of a 3D stereoscopic sequence through a system of prisms whose optical power was repeatedly varied. In [24,39], YANO et al. presented an experiment in which observers visualized 3D stereoscopic sequences under viewing conditions that minimized the accommodation - vergence conflict (limited disparity and appropriate viewing distance). Even so, both fatigue and discomfort were reported when visual- 
ized sequences featured a large amount of in-depth motion. Finally, another study [76] showed that the speed of in-depth movements may have a determining influence on discomfort: discomfort increased with in-depth motion speed.

Planar movements, without variations in depth, have also been studied in relation to fatigue and discomfort. In $[39,24]$, contrary to in-depth movements, planar movements had no influence on fatigue nor discomfort. Conversely, in [77], the visualization of a 3D stereoscopic Maltese cross moving on a circular and planar path induced increasing discomfort with increasing angular speed. In the same study, discomfort also increased with the depth interval separating the moving cross from the background, regardless of the amount of accommodation - vergence conflict.

\subsubsection{Limited depth-of-field}

The depth-of-field is defined as the range of distances, in the real world, that appear in sharp focus, thus specified in meters. The depth-of-focus is the projection of the depth-of-field within the image space, through the optical system (the eyes or the cameras) and is expressed in diopters $( \pm 0.2 \delta$ for the eyes [39]). In $3 \mathrm{D}$ stereoscopic imaging systems, depth-of-focus refers to the depth range in front of and behind the screen within which displayed objects are in sharp focus [78].

Usually, the visual system only performs binocular fusion in areas whose retinal image is in sharp focus. While in the real world, depth-of-field and fusion range generally concur, there is a risk that excessive disparities in $3 \mathrm{D}$ stereoscopic system may image objects outside of the depth-of-focus. Some researchers argued that this may be a source for discomfort $[13,78]$.

The depth-of-focus depends on the optical parameters, thus is influenced by numerous factors that notably include viewing distance, aperture and optical aberrations. It monotonically increases with the viewing distance: the role of focus accommodation decreases with increasing viewing distances.

For the eyes, the aperture is given by the pupil's size: the smaller the pupils, the larger the depth-of-focus [7982]. In turn, the pupil size is affected by the luminance [83]: the more light, the smaller the pupil, the larger the depth-of-focus. This is especially important with active stereoscopic displays, whose shutter glasses reduce the luminance by $80 \%$ : a minimum level of $30 \mathrm{~cd} / \mathrm{m}^{2}$ at a distance of 2 meters is advised [9], to sustain an acceptable depth-of-focus. Finally, in [84], Li and Sun showed that pupillary response could be induced by the visualization of moving autostereograms: the pupil thus also reacts to disparity.
In addition to pupillary aspects, depth-of-focus is influenced by all kinds of optical aberrations (or anomalies). These include accommodative dysfunctions and refractive errors (e.g. presbiopia) [80,85-87]. Such anomalies may as well reduce or enlarge depth-of-focus; in the latter scenario [85-87], it was argued that these anomalies may contribute to limit visual fatigue [61].

\subsection{Cognitive limitations and anomalies}

Besides ocular and oculomotor mechanisms, depth perception brings into play numerous cognitive functions in charge of processing left and right retinal images. For many reasons (anomalies, intrinsic behavior), some of these cognitive functions may not operate properly when presented with a binocular stimulus, thus possibly resulting in unusual cognitive loads.

\subsubsection{Retinal disparity identification: cortical anomalies}

In [88], subjective experiments were conducted to determine how disparities are processed by the visual cortex. Later, experiments were conducted in monkeys in [89, 90]. Results suggest the existence of at least three sets of cortical neurons, called disparity-tuned visual channels, that would respectively be stimulated by crossed, uncrossed and near-null disparities. The channel whose response is highest (see Figure 4) would then define the perceived disparity. Later, it was proposed in [91] that there are no such channels, but rather a continuous set of cortical neurons each tuned to specific orientations or amplitudes of disparity.

In [9], PAtTerson argued that asymmetric distributions of these neurons may explain unbalanced sensitivities to disparities. Possible consequences include stereo-blindness and stereo-anomaly. Stereo-blindness affects $6 \%$ to $8 \%$ of the population and may be explained by the absence of disparity detectors [88]; it completely prevents observers to perceive depth in most displays. Stereo-anomaly is a cognitive disorder where crossed disparities are perceived as uncrossed disparities (or vice-versa). It was reported for $20 \%$ to $30 \%$ of the population and occurs mostly when viewing conditions are degraded (e.g. brief exposure) [92]. While it still enables depth perception, stereoanomaly introduces sporadic depth discrepancies, which were considered by some as a possible source of fatigue and discomfort [9]. 


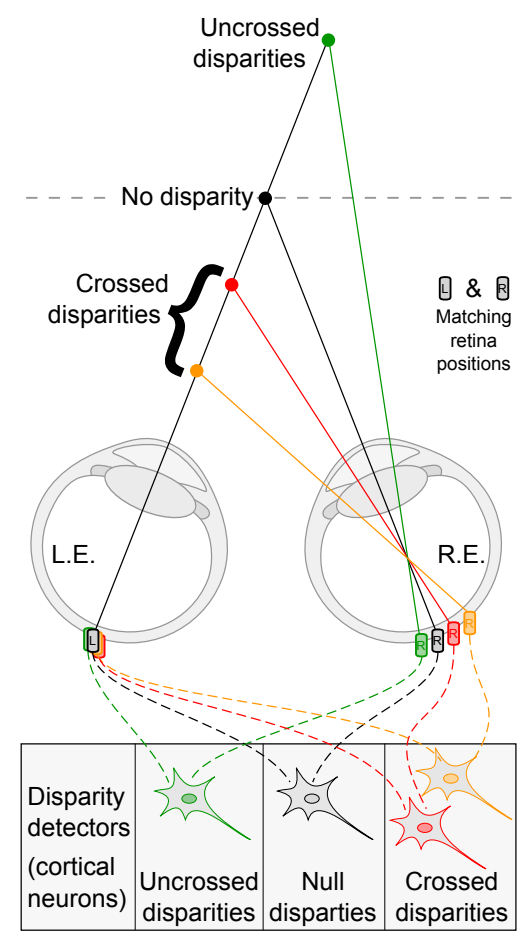

Fig. 4 Disparity tuned channels: cortical neurons acting as disparity detectors match corresponding retina positions. The disparity is given by neurons whose response is highest.

\subsubsection{A limited binocular fusion range}

Stereopsis builds the depth information relative to a reference surface, called horopter: the set of 3D positions from the real world that stimulate matching points on left and right retinas. In other words, the horopter is the surface of zero retinal disparity. It was first theoretically modeled in the the $19^{\text {th }}$ century by G. VIETH then J. MüLLER, model later called Vieth-Müller circle [93]. Any position that does not belong to the horopter thus generates retinal disparity. The set of positions, located both sides of the horopter, for which binocular fusion is possible form a zone called Panum's area. Beyond, retinal images cannot be fused; this leads to diplopia (double vision), binocular rivalry (perception alternatively switches between left and right views) or eye suppression (a single view is perceived) [94-96].

Numerous factors influence the extent and shape of Panum's area. First studies reported dimensions ranging from 14 arcmin [97] to 120 arcmin [98]. Nowadays, Panum's area is considered to spread 40 arcmin [9]. Initially described as an elliptical surface [96], later studies showed that its extent increases with the eccentricity of the stimulus [99]. These results support the fact that the fusion range increases with the viewing angle [100] in stereoscopic displays.

The extent of Panum's area increases with stimulus size, illumination, exposure duration [101] and training
[102]. Conversely, it decreases when the stimulus' spatial frequency is increased $[96,103]$ and when the temporal frequency modulation of the disparity is increased [96]. The visualization of 3D stereoscopic contents featuring small, badly illuminated, high frequency which frequently move in-depth may thus contribute to reduce Panum's area. In turn, resulting episodes of diplopia or binocular rivalry might induce fatigue and discomfort [57]. Ensuring that imaged stereoscopic contents fall within Panum's area is thus a key factor in limiting fatigue and discomfort. However, this requires determining the perceived retinal disparity from the screen disparity, which is not trivial: retinal disparity depends on all kinds of factors, including retinal shape [104] and horopter shape [105], thus varies from person to person.

In [105], SCHREIBER et al. showed that the horopter is shaped as a surface curved outwards (see Figure 5b), whose profile is slanted backwards (see Figure 5a) [105, 106]. Such a profile seemed to be adapted to natural scenes in which close objects are at the bottom of the visual field, while far objects are located at the top of the visual field (e.g. clouds). This may be linked to a study [75] in which NOJIRI et al. showed that 3D stereoscopic sequences featuring crossed disparities at the bottom of the screen and uncrossed disparities at the top of the screen generated less discomfort than others. In a recent study [106], however, results suggested that the horopter's shape is adapted to the perception of convex slanted surfaces at short distances, but not to disparity distributions in natural scenes relative to the ground. In the same study, CoOper and Burge described an experiment where observers wore deforming lenses for five days; results showed that the shape of the horopter did not adapt to the presented deformation, hence it may not be adaptive (not changeable by experience).

\subsubsection{Duality of binocular perception}

Central and peripheral visual field areas are differently processed by the visual cortex and generate different kinds of information $[107,108]$. The parvocellular-dominated pathway connects the central retina, or fovea, to the visual cortex ventral-cortical stream. On one end, the fovea is mostly (and densely) paved with cone cells, sensitive to color. On the other end, the visual cortex ventral-cortical stream brings into play neurons whose responses are slow and sustained. Thus, high spatial frequencies are detected in the central area of the visual field, while fast temporal changes are not. Conversely, the magnocellular-dominated pathway connects the peripheral retina, to the visual cortex dorsal-cortical stream. On one end, the peripheral retina is sparsely paved with cone cells. On the other end, the visual 


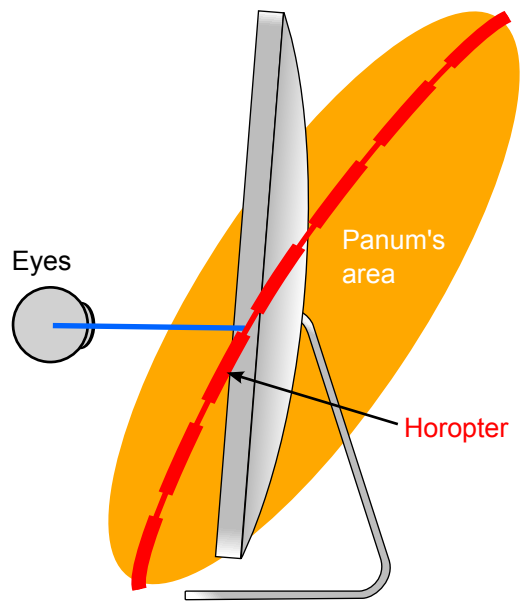

(a) Side-sectional view of panum's area and the horopter

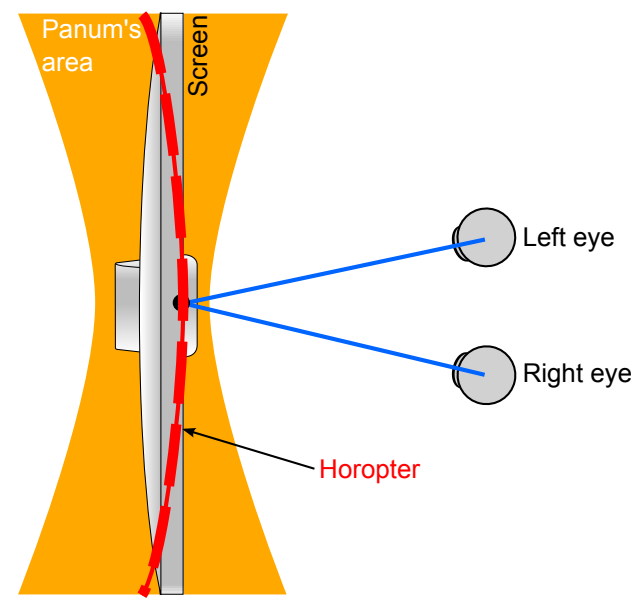

(b) Top-sectional view of Panum's area and the horopter

Fig. 5 Horopter and Panum's area: simplified localization and shapes

cortex dorsal-cortical stream brings into play neurons whose responses are fast and transient. Hence, the peripheral visual area is suited to coarse detection of the optical flow and motion perception.

This duality is also to be found in stereopsis. Several studies $[96,109,103,110]$ show that the visualization of static or slowly moving stimuli featuring high spatial frequencies brings into play a high stereo-acuity but a low fusion range. Conversely, the visualization of low frequency stimuli undergoing rapid movements brings into play a low stereo-acuity but a large fusion range. Former and latter scenarios suggest the respective use of parvocellular and magnocellular pathways [9]. Some researchers also introduced the notions of patent and qualitative stereopsis [111]. With patent stereopsis, the perceived depth monotonically increases with retinal disparity; with qualitative stereopsis, fusion is more difficult and only generates a coarse depth information relative to an object (e.g. behind versus in front of), but operates on a disparity range much larger than the fusion range. In [112], STRANSKY and WILCOX suggested that this dichotomy may be due to the existence of two separate cortical mechanisms.

It is worth noting that the proposed duality correlates well with the increasing extent of Panum's area with eccentricity [99]: Panum's area is maximal in peripheral vision. For all these reasons, the visualization of $3 \mathrm{D}$ stereoscopic sequences is likely to be facilitated if objects featuring in-depth motion and large amounts of disparity are imaged in peripheral vision. Conversely, objects featuring detailed depth information should be imaged in central vision.

\subsubsection{Depth cues and cognitive conflicts}

Depth perception does not solely rely on retinal disparity, but employs a variety of cognitive and physiological cues which may be monocular or binocular. In [113], for instance, BINGHAM et al. showed that observers movements, by generating motion parallax, may compensate at short distance the absence of binocular parallax. Numerous reviews discussed the different depth cues; the interested reader is notably advised to consult CUTTING and VisHTON's comprehensive review [114].

The human visual system features integration mechanisms in charge of building the depth percept from the available depth cues. Some researchers $[61,115,116]$ argued that the final depth may be built through statistical inference: i.e. the amount of depth which best correlates with each depth cue individually. Conversely, some suggested the existence of deterministic processes linking the different values of individual depth cues to given amounts of depth $[117,118]$. In [118], Domini et al. proposed a model in which maximum likelihood is used to estimate the linear relationship between the disparity and the movement of an object; this estimate is used to determine the perceived depth.

Patterson [9,10], Ono and Comerford [119], NAKAMizo [120] and Richards [121] proposed that the relative depth information provided by the retinal disparity may be translated into absolute depth using other depth cues; this model is known as distance scaling of disparity. Furthermore, some researchers showed that monocular cues such as occlusions [122] and contours [123] may be used by the visual system in order to determine whether binocular fusion needs to be solicited. Finally, some researchers suggested the existence of a mental representation of the structure of the 
visual field that is built over time [11]. Serving as a prediction, such an information may considerably simplify the integration process.

3D stereoscopic imaging systems, however, render the depth by introducing artificial depth cues. While studies are missing, some researchers argued that the introduction of inappropriate or incoherent cues may complicate the integration process [10], thus possibly resulting in unusual cognitive load, fatigue and discomfort. For instance, left and right views inversion introduces conflicting monocular and binocular cues to the visual system; a study showed that this inversion may cause discomfort [124]. The presence of objects in front of the screen, cut by the display frame, may also induce visual discomfort [125]; this is known as stereoscopic window violations. Another issue possibly lies in the fact that, in stereoscopic displays, the entire scene is rendered sharply, while in the real world areas located outside of the depth-of-field are not in focus and do not solicit binocular fusion. In the absence of more exhaustive studies, researchers generally advise to ensure that proposed depth cues be as consistent as possible [126, $10,61,127]$.

\section{Application to 3D stereoscopic displays and contents}

We will now discuss how the issues raised in previous sections impact 3D stereoscopic displaying technologies and contents.

\subsection{A comfortable range of fusion}

In order to minimize the accommodation - vergence conflict and to ensure adapted depth-of-focus, it is generally suggested to image contents within a comfort zone. It is given by the depth budget, in front of and behind the screen (see Figure 6) within which stereoscopic contents appear inside the fusion range (thus avoiding diplopia, binocular rivalry and eye suppression) and inside the depth-of-focus (otherwise contents should be blurred).

Decades ago, Percival [128] then Sheard [129] proposed empirical limits for a comfortable fusion zone. Nowadays, the comfort zone is specified in various ways: \pm 0.2 diopters in terms of depth-of-focus [24,78], $\pm 1^{\circ}$ of angle of screen disparity $[13,76]$, or $1 \%$ and $2 \%$ respectively of crossed and uncrossed disparities in terms of screen width [125]. Any of these definitions lead to similar depth intervals. In Figure 7, they were each plotted for various viewing distances and a 42 " screen with $16 / 9$ aspect ratio.

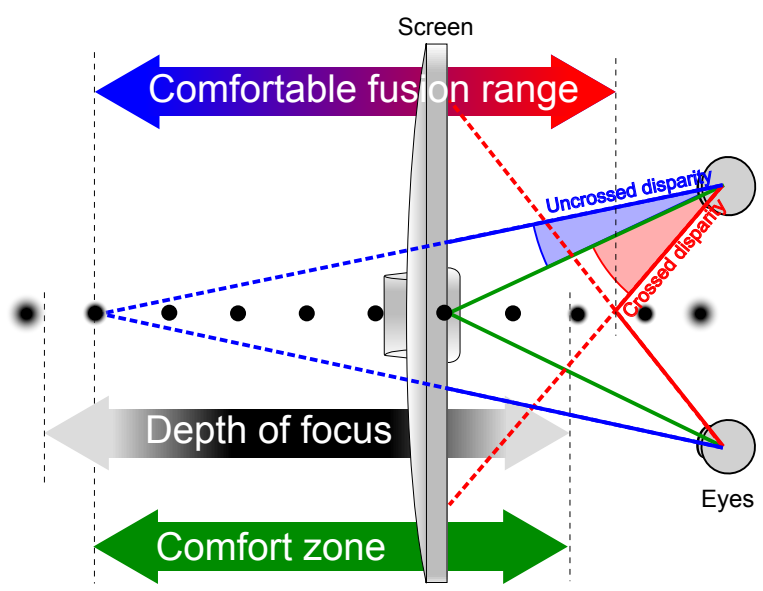

Fig. 6 Viewing distance, depth-of-focus and fusion range. An object (black disk) is imaged at various depth and appears blurred outside of the depth-of-focus. The comfort zone is given by the intersection between the comfortable fusion range and the depth-of-focus.

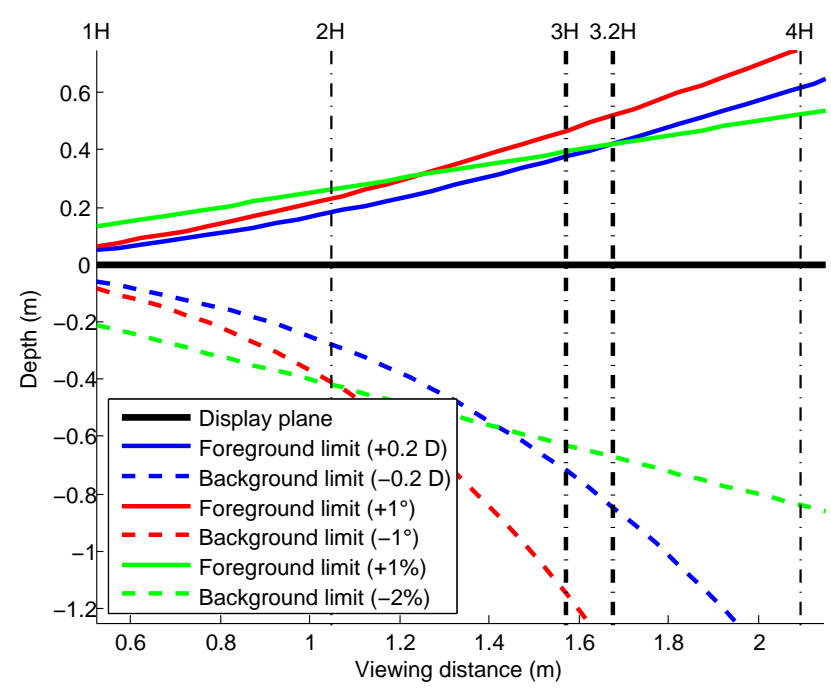

Fig. 7 Proposed comfort zones at various viewing distances for a 42 " screen of ratio 16/9. Preferred viewing distances proposed in Video Quality Expert Group (VQEG) test plan [130] $(3 H)$ and ITU-R BT.2022 [131] $(3.2 H)$ are plotted on vertical dash-dotted lines $-H$ is the screen height.

\subsection{Camera artifacts}

Shooting, post-processing and rendering artifacts can introduce matching errors between left and right stereoscopic views. Toed-in cameras, for instance, generate vertical disparities [132]; SpERANZA and WILCOX showed in [133] that the global introduction of vertical disparity caused visual discomfort, which increased with the amplitude of the vertical shift and the exposure duration. Similar results were presented in [134]. In [135], visual discomfort was reduced when keystoning, a trapezoidal distortion also introduced by toed-in cameras [132], was compensated at post-processing. Similarly in 
[134], Koor and ToET showed that keystoning effects greater than $1 \delta_{\Delta}$ causes discomfort. In the same study, rotations with angles greater than $1^{\circ}$ and scaling effects greater than $2.5 \%$ also caused discomfort.

\subsection{Compression and transmission artifacts}

In [8], BARKOWSKY et al. showed that coding artifacts may induce discomfort: the percentage of observers reporting discomfort increased with the quantization step of H.264 codec. Transmission errors, in particular packet losses, may impair differently left and right views, which possibly results in binocular rivalry. In $[8,136]$, despite the use of various error concealment strategies, concealed views still caused discomfort. In the same study, a subjective test showed that observers prefer to temporarily switch to $2 \mathrm{D}$.

\subsection{Rendering artifacts}

3D stereoscopic displaying technologies suffer from various defects. Low refresh rates and interferences between active shutter glasses and some neon lighting devices operating at low frequencies $(50 \mathrm{~Hz}, 60 \mathrm{~Hz})$, for instance, cause interference that can be especially problematic when perceived in peripheral vision. Few works proposed comparative studies between different display technologies with respect to fatigue or discomfort. In [137], SLALINA et al. compared passive LCD, active plasma and active projection display systems in terms of QoE. Their results showed no difference in discomfort between the three; yet, ambient light proves to be more disturbing in active displays, possibly because of interference from neon lights are used to illuminate the room. In another study [138], YANG et al. compared an active to a passive LCD display; their results tend to show that the use of passive glasses, ideally with incorporated optical correction, are less intrusive than shutter glasses and may generate less fatigue and less discomfort.

Crosstalk is probably the most studied display technology artifact. Widely spread in both active and passive displays $[139,140]$, it occurs when an information intended to one eye leaks to the other eye. Crosstalk is generally perceived as blurring or ghosting effects, which in turn cause discomfort [141]. In [134], slight discomfort was induced by the introduction of $5 \%$ of crosstalk; major discomfort was induced when crosstalk reached $25 \%$. However, in [142], the controlled introduction of crosstalk helped diminishing the discomfort caused by picket fence effects when an observer changed the viewing position in front of an autostereoscopic display.

Finally, when stereoscopic views are synthesized from depth maps or by 2D-to-3D conversion [143, 144], temporal discrepancies such as depth oscillations or turbulence around the edges may also generate discomfort $[13,145]$.

\subsection{Effects of focus and defocus}

Several studies showed that, in the presence of conflicting demands in accommodation and vergence, the role of focus accommodation decreased with increasing amounts of blur $[68,69]$. Conversely, sharply imaged contents featuring high frequencies may be more demanding to visualize as focus accommodation needs to be accurate. Yet, in [134], the introduction of a small amount of blur caused significant discomfort.

Blur was long considered to be a weak depth cue [146]: its symmetry with respect to the focus point makes it ambiguous as an information source. Yet, a recent study [116] showed that the amount of blur is proportional to the disparity; HELD et al. showed that the perceived depth could be modified purely by introduction of blur. In [147], an experiment showed that the introduction of blur could increase the perceived depth, as a function of the distance separating the foreground and the background of the visualized scene.

Studies showed that the distribution of defocus blur with respect to the depth may have a significant impact on the perceived depth $[116,147]$. Introducing defocus blur may then provide a way to enhance the perceived depth range while minimizing the accommodation vergence conflict [147]. In other words, artificial blur may be used to reduce screen disparity while maintaining the same amount of perceived depth. While studies are missing, this suggests that artificial blur could be used to minimize the accommodation - vergence conflict and to diminish the role of focus accommodation.

\subsection{Visual attention}

Visual attention has been shown to interact with numerous perceptual mechanisms [148] brought into play by $3 \mathrm{D}$ contents. It performs a selection amongst elements presented in the visual field and thus determines the perceived stimuli. Previous sections listed many mechanisms in which stimuli characteristics influence the limits of depth perception. For instance, depthof-focus depends on the size of the object of interest [149]. The vergence load varies in time and space with 
the depth of perceived objects. Panum's area dimensions increase with stimuli eccentricity: salient objects, likely to be perceived in central vision, should present with a limited disparity in comparison to objects perceived in peripheral vision. In other words, the characteristics of salient elements in stereoscopic 3D contents are very likely to be crucial with respect to fatigue and discomfort.

Recent research efforts have been focusing on 3D visual attention and its possible link with discomfort. In a recent study [150], ZHANG et al. proposed a model for 3D visual attention that is based on depth, luminance, color and motion contrast. Even more recently, in [151], a 3D visual attention model is used to build an objective model for discomfort in 3D stereoscopic sequences. A similar model can be found in [152].

\subsection{Discrepant or nonexistent motion parallax}

Motion parallax, also called monocular disparity, corresponds to the depth information provided by the observer's movements: the temporal succession of different views of the same scene at slightly different angles provides a valuable depth information. 3D stereoscopic displays do not render this effect, but rather induce a feeling of flatness [14], or modify the shape of the 3D effect [153]. The scene is compressed in depth when the observer gets closer to the display plane and shears when he moves from left to right [153]. Some researchers suggested that these effects may introduce cognitive conflicts and generate fatigue or discomfort [14]. In multiview autostereoscopic systems, however, motion parallax can be simulated and thus minimizes depth shearing effects.

\subsection{Exposure duration and training effects}

There are indications that visual fatigue may be accumulated: increasing viewing durations may also increase the duration and the amplitude of the visual symptoms. Such effects are well-known with 2D displays $[40,41]$. In [154], for instance, visual evoked cortical potentials were increasingly delayed, day after day, in 2D display terminal workers. Similar studies exist with 3D displays. In [155], for instance, the accommodation speed was unchanged after 15 minutes of $3 \mathrm{D}$ stereoscopic visualization but decreased after 30 minutes of exposure. In the latter scenario, 90 to 120 minutes were required for the observers' visual system to retrieve baseline performances. With short term fatigue induced by the visualization of 3D sequences, however, experiments showed that affected visual functions recovered very rapidly [15]. In [55], finally, the cortical activity from the beta band increased with exposure duration to a $3 \mathrm{D}$ stereoscopic sequence.

Over time, however, training may increase the performances of the visual system in perceiving depth. In $[101,102]$, Woo, Jones and Stephens showed that Panum's area dimensions increased with visualization time. In [15], results showed a short-term increase of the fusion range after stereoscopic visualization. In [57], fusion range increased when repeated experimental sessions were conducted with the same observer. These observations suggest that training may contribute to reduce fatigue and discomfort.

\subsection{Towards objective models for fatigue and} discomfort

Some researchers now aim at building objective models to automatically predict visual fatigue and discomfort from 3D contents to be visualized. In [156], CHOI et al. proposed a model for fatigue based on spatial and temporal characteristics of the disparity. Linear regression was conducted on the model's parameters to best match absolute category rating (ACR) scores for fatigue. In [145], they modified their model to fit ACR discomfort scores. Results showed that predicted discomfort correlated well with subjective scores. Finally, in [65], the authors introduced a discomfort model which is based on eye blinking rate.

\section{Conclusion}

In this paper, we reviewed visual fatigue and visual discomfort that are induced by the visualization of $3 \mathrm{D}$ stereoscopic contents. We first listed many of the effects of fatigue and discomfort. Most disorders are of ocular nature and affect the near triad (accommodation, vergence and pupillary response). However, some studies also demonstrate evidence for cognitive changes induced by visual fatigue and discomfort. Both these aspects were discussed in the light of ocular, oculomotor, cortical and cognitive processes enabling depth perception. The accommodation - vergence conflict is wellknown and constrains 3D contents to be imaged within a comfort zone; however, content's motion should also be considered as it may induce discomfort or fatigue despite being imaged within this zone.

Despite the very limited number of studies focusing on cognitive aspects of fatigue and discomfort, there is evidence that cognitive processes enabling depth perception may also induce fatigue and discomfort. Stereo- 


$\begin{array}{ll}\text { Content characteristics } & \text { Viewing conditions } \\ \text { - Limit fast movements, especially if in-depth or in the central } & \bullet \text { Avoid compression or transmission artifacts } \\ \text { visual field. } & \text { that impair left and right view independently. } \\ \text { - Avoid scenes with large depth separation between foreground and } & \bullet \text { Minimize rendering artifacts, notably the } \\ \text { background. } & \text { crosstalk. } \\ \text { - Eventually prefer blur to more disparity in order to increase the } & \bullet \text { Ensure minimum illumination to sustain } \\ \text { perceived depth. } & \text { required depth-of-focus. } \\ \text { - Pay particular attention to salient objects (visual attention). } & \text { - Prefer lightweight and non-intrusive 3D } \\ \text { - Check for incoherent depth cues (e.g. window violation). } & \text { glasses in stereoscopic displays. } \\ \text { - Limit exposure duration to large 3D effects (e.g. pop-out effects). } & \text { Avoid strong ambient illumination (especially } \\ \text { - Limit or compensate camera artifacts (e.g. vertical disparity). } & \text { interfering lighting). }\end{array}$

Table 1 A few guidelines for best experience in 3D stereoscopy

anomaly, for instance, is quite frequent and may input discrepant disparity information to the visual cortex. The range of binocular fusion is best described by Panum's area; empirical values for the comfort zone only provide an extremely crude approximation of this area as all kind of content characteristics (spatial and temporal frequency, size, illumination, eccentricity) influence Panum's area. In terms of accuracy and speed, depth perception also depends on the visual pathway taken (central or peripheral visual field). Finally, some researchers suggest that incoherent depth cues may as well generate discomfort.

In practice, the $3 \mathrm{D}$ value chain brings numerous artifacts and constraints that impair the QoE. Shooting, compression and transmission artifacts, for instance, introduces impairments that are known to generate discomfort. However, there are a few guidelines that, if respected, can limit the occurrence of discomfort or fatigue. Some of them are summarized in Table 1. While there is a small number of comparative studies between $3 \mathrm{D}$ displaying technologies, it appears that active and passive, LCD-based and projection-based technologies perform similarly; the glasses, however, seem to influence discomfort and fatigue.

Research on visual fatigue and visual discomfort with displays fall within multiple disciplines notably including psychophysics, ophthalmology, psychology and applied research on displaying technologies. Terminologies vary from domain to domain; visual fatigue, strain and asthenopia, for instance, are co-existing terms whose definitions may be overlapping. The existence of a common terminology may ease interdisciplinary transfers of knowledge.

This review also highlights potential directions for future research. The development of models for visual fatigue and discomfort should be encouraged, as this will provide objective tool for QoE evaluation. The same holds true for refined models of the fusion range taking into account the contents characteristics. The investigation of cognitive processes in charge of the perception of depth, under discomfort or fatigue, may also provide extremely valuable knowledge.

\section{References}

1. N. Holliman, N. A. Dodgson, G. E. Favalora, L. Pockett, Three-Dimensional Displays: A Review and Applications Analysis, IEEE Trans. on broadcasting 57 (2) (2011) 362-371.

2. Qualinet, Qualinet White Paper on Definitions of Quality of Experience, Tech. rep., Dagstuhl Seminar (2012).

3. P. J. Seuntiens, W. A. IJsselsteijn, P. M. J. Van Den Avoort, J. Berentsen, I. J. Dalm, M. T. M. Lambooij, W. Oosting, I. Heynderickx, Viewing experience and naturalness of 3D images, Vol. 31, SPIE, 2005.

4. P. J. H. Seuntiëns, I. E. J. Heynderickx, W. A. IJsselsteijn, Capturing the Added Value of ThreeDimensional Television: Viewing Experience and Naturalness of Stereoscopic Images, J. of Imaging Science and Tech. 52 (2).

5. A. Benoit, P. Le Callet, P. Campisi, R. Cousseau, Quality Assessment of Stereoscopic Images, EURASIP J. on Image and Video Proc. 2008 (2008) 1-13.

6. M. T. M. Lambooij, W. A. Ijsselsteijn, D. G. Bouwhuis, I. Heynderickx, Evaluation of Stereoscopic Images : Beyond 2D Quality, IEEE Transactions on broadcasting 57 (2) (2011) 432-444.

7. W. A. IJsselsteijn, Presence in Depth, Ph.D. thesis, Eindhoven University of Technology (2004).

8. M. Barkowsky, K. Wang, R. Cousseau, K. Brunnström, R. Olsson, P. Le Callet, Subjective quality assessment of error concealment strategies for 3DTV in the presence of asymmetric transmission errors, IEEE, Hong Kong, 2010.

9. R. Patterson, Human factors of 3-D displays, Journal of the Society for Information Display 15 (11) (2007) 861-871.

10. R. Patterson, Review Paper: Human factors of stereo displays: An update, Journal of the Society for Information Display 17 (12) (2009) 987.

11. K. Ukai, P. A. Howarth, Visual fatigue caused by viewing stereoscopic motion images: Background, theories, and observations, Displays 29 (2) (2008) 106-116. 
12. W. J. Tam, F. Speranza, S. Yano, K. Shimono, H. Ono, A. H. S. Vision, Stereoscopic 3D-TV : Visual Comfort, IEEE Trans. on broadcasting 57 (2) (2011) 335-346.

13. M. T. M. Lambooij, W. A. Ijsselsteijn, I. Heynderickx, Visual discomfort in stereoscopic displays: a review, Proc. SPIE 6490.

14. P. A. Howarth, Potential hazards of viewing 3-D stereoscopic television, cinema and computer games: a review., Ophthalmic \& physiological optics : the journal of the British College of Ophthalmic Opticians (Optometrists) 31 (2) (2011) 111-22.

15. M. T. M. Lambooij, M. F. Fortuin, W. A. Ijsselsteijn, I. Heynderickx, Measuring visual discomfort associated with 3D displays, Proc. SPIE 7237 (2009) 12.

16. M. Barkowsky, R. Cousseau, P. Le Callet, Is visual fatigue changing the perceived depth accuracy on an autostereoscopic display?, SPIE Electronic Imaging: Stereoscopic Displays and Applications 7863 (6597) (2011) 1-8.

17. R. Kennedy, N. Lane, K. Berbaum, M. Lilienthal, Simulator Sickness Questionnaire: An Enhanced Method for Quantifying Simulator Sickness, The International Journal of Aviation Psychology 3 (3) (1993) 203-220.

18. P. Howarth, P. Costello, The occurrence of virtual simulation sickness symptoms when an HMD was used as a personal viewing system, Displays 18 (2) (1997) 107116.

19. S. Ohno, K. Ukai, Subjective evaluation of motion sickness following game play with head mounted display, Journal of the Institute of Image Information and Television Engineers 54 (6) (2000) 887-891.

20. R. M. Schiffman, M. D. Christianson, G. Jacobsen, J. D. Hirsch, B. L. Reis, Reliability and validity of the Ocular Surface Disease Index., Archives of ophthalmology 118 (5) (2000) 615-21.

21. M. Ogata, K. Ukai, T. Kawai, Visual Fatigue in Congenital Nystagmus Caused by Viewing Images of Color Sequential Projectors, J. of Display Tech. 1 (2) (2005) 314-320.

22. A. Suzumura, Ocular fatigue, Ganka 23 (1986) 799-804.

23. S.-n. Yang, T. Schlieski, B. Selmins, S. Cooper, R. Doherty, P. J. Corriveau, J. E. Sheedy, Individual Differences and Seating Position Affect Immersion and Symptoms in Stereoscopic 3D Viewing, in: Proc. of Stereoscopic Displays And Applications, Vol. 7863, 2011, pp. $1-44$.

24. S. Yano, S. Ide, T. Mitsuhashi, H. Thwaites, A study of visual fatigue and visual comfort for 3D HDTV/HDTV images, Displays 23 (4) (2002) 191-201.

25. ITU-R-BT.500-11, Methodology for the subjective assessment of the quality of television pictures, Tech. rep., International Telecommunication Union (2004).

26. T. Shibata, J. Yoshitake, Y. Koido, K. Kikuchi, T. Kawai, Ergonomic Evaluation of Visual Discomfort with Autostereoscopic Displays, SID Symposium Digest of Technical Papers 43 (1) (2012) 129-132.

27. J. P. Wann, M. Mon-Williams, Measurement of visual aftereffects following virtual environment exposure, in: K. M. Stanney (Ed.), Handbook of virtual environments: design, implementation, and applications, 2002, Ch. 37, pp. 731-749.

28. T. Ando, A. Tanaka, S. Fukasaku, R. Takada, M. Okada, K. Ukai, K. Shizuka, H. Oyamada, H. Toda, T. Taniyama, T. Usui, M. Yoshizawa, T. Kiryu, M. Takagi, S. Saida, T. Bando, Pupillary and cardiovascular responses to a video movie in senior human subjects.,
Autonomic neuroscience : basic \& clinical 97 (2) (2002) 129-35.

29. H. Nagatani, Y. Hirayama, Evaluation of the influence on the human body of the autostereoscopic display based on the integral imaging method, Proc. SPIE 6803 (2008) 1-8.

30. F. Cail, S. Salsi, La fatigue visuelle, Tech. Rep. 1-3, INRS (1992).

31. W. Jaschinski, M. Bonacker, E. Alshuth, Accommodation, convergence, pupil diameter and eye blinks at a CRT display flickering near fusion limit., Ergonomics 39 (1) (1996) 152-64.

32. S. Saito, Does fatigue exist in a quantitative measurement of eye movements?, Ergonomics 35 (5-6) (1992) 607-15.

33. C.-F. Chi, F.-T. Lin, A Comparison of Seven Visual Fatigue Assessment Techniques In Three Data-Acquisition VDT Tasks, Human Factors: The Journal of the Human Factors and Ergonomics Society 40 (4) (1998) 577-590.

34. C. Blehm, S. Vishnu, A. Khattak, S. Mitra, R. W. Yee, Computer vision syndrome: a review., Survey of ophthalmology 50 (3) (2005) 253-62.

35. D. L. Ehrlich, Near vision stress: vergence adaptation and accommodative fatigue, Ophthalmic and Physiological Optics 7 (4) (1987) 353-357.

36. S. Ebenholtz, Accommodative hysteresis as a function of target-dark focus separation, Vision Research 32 (5) (1992) 925-929.

37. W. Jaschinski-Kruza, Visual strain during VDU work; the effect of viewing distance and dark focus, Ergonomics 31 (1998) 1449-65.

38. S. Hasebe, E. W. Graf, C. M. Schor, Fatigue reduces tonic accommodation, Ophthalmic and Physiological Optics 21 (2) (2001) 151-160.

39. S. Yano, M. Emoto, T. Mitsuhashi, Two factors in visual fatigue caused by stereoscopic HDTV images, Displays 25 (4) (2004) 141-150.

40. A. Uetake, A. Murata, M. Otsuka, Y. Takasawa, Evaluation of visual fatigue during VDT tasks, in: Proceedings of IEEE International Conference on Systems, Man and Cybernetics, IEEE, Nashville, TN, USA, 2000, pp. 1277-1282.

41. A. Murata, A. Uetake, M. Otsuka, Y. Takasawa, Proposal of an Index to Evaluate Visual Fatigue Induced During Visual Display Terminal Tasks, International Journal of Human-Computer Interaction 13 (3) (2001) 305-321.

42. A. Ivanoff, Night Binocular Convergence and Night Myopia, Journal of the Optical Society of America 45 (9) (1955) 769_1.

43. M. Kromeier, C. Schmitt, M. Bach, G. Kommerell, Stereoacuity versus fixation disparity as indicators for vergence accuracy under prismatic stress., J. of the British College of Ophthalmic Opticians 23 (1) (2003) 43-9.

44. E. Chetty, S. Jackson, C. Mitton, T. K. Philips, A review of fixation disparity, The south african optometrist 66 (4) (2007) 192-197.

45. W. Jaschinski-Kruza, Eyestrain in VDU users: viewing distance and the resting position of ocular muscles., $\mathrm{Hu}-$ man factors 33 (1) (1991) 69-83.

46. W. Jaschinski-Kruza, The proximity-fixation-disparity curve and the preferred viewing distance at a visual display as an indicator of near vision fatigue, Optometry and vision science: official pub. of the Am. Ac. of Optometry 79 (3) (2002) 158-69. 
47. R. North, D. B. Henson, Adaptation to prism-induced heterophoria in subjects with abnormal binocular vision or asthenopia., American journal of optometry and physiological optics 58 (9) (1981) 746-52.

48. S. K. Fisher, K. J. Ciuffreda, S. Levine, K. S. WolfKelly, Tonic adaptation in symptomatic and asymptomatic subjects., American journal of optometry and physiological optics 64 (5) (1987) 333-43.

49. G. K. Hung, Models of Oculomotor Control, Vol. 55, World Scientif Publishing Co. Pte. Ltd., 2001.

50. K. Ukai, H. Oyamada, S. Ishikawa, Changes in accommodation and vergence following 2 hours of movie viewing through bi-ocular head-mounted diplay, in: O. Franzén, H. Richter, L. Stark (Eds.), Accommodation and vergence mechanisms in the visual system, Birkhaüser Verlag, 2000, pp. 313-325.

51. C. M. Schor, T. K. Tsuetaki, Fatigue of accommodation and vergence modifies their mutual interactions., Inv. ophth. \& vis. science 28 (8) (1987) 1250-9.

52. Y. Nakamura, Measurement of pupillary unrest in eyestrain., Japanese journal of ophthalmology 40 (4) (1996) $533-9$.

53. K. Ukai, K. Tsuchiya, S. Ishikawa, Induced pupillary hippus following near vision: increased occurrence in visual display unit workers., Ergonomics 40 (11) (1997) 1201-11.

54. H. Bouma, L. Baghuis, Hippus of the pupil: Periods of slow oscillations of unknown origin, Vision Research 11 (11) (1971) 1345-1351.

55. H. Li, J. Seo, K. Kham, S. Lee, Measurement of 3D visual fatigue using event-related potential (ERP): 3D oddball paradigm, in: 3DTV Conference: The True Vision-Capture, Transmission and Display of 3D Video, 2008, IEEE, 2008, pp. 213-216.

56. M. Emoto, Y. Nojiri, F. Okano, Changes in fusional vergence limit and its hysteresis after viewing stereoscopic TV, Displays 25 (2-3) (2004) 67-76.

57. M. Emoto, T. Niida, F. Okano, Repeated Vergence Adaptation Causes the Decline of Visual Functions in Watching Stereoscopic Television, Journal of Display Technology 1 (2) (2005) 328-340.

58. Y. Nojiri, H. Yamanoue, A. Hanazato, M. Emoto, F. Okano, Visual comfort/discomfort and visual fatigue caused by stereoscopic HDTV viewing, in: Proceedings of SPIE, Vol. 5291, SPIE, 2004, pp. 303-313.

59. B. J. W. Evans, Pickwell's binocular vision anomalies: investigation and treatment, 4th Edition, ButterworthHeinemann, 2002.

60. M. T. M. Lambooij, M. F. Fortuin, W. A. Ijsselsteijn, I. Heynderickx, Visual discomfort associated with 3D displays, in: 5th Int.Workshop on Video Proc. and Quality Metrics (VPQM), 2010, p. 6.

61. D. M. Hoffman, A. R. Girshick, M. S. Banks, Vergence accommodation conflicts hinder visual performance and cause visual fatigue, J. of Vision 8 (3) (2008) 1-30.

62. J. Kuze, K. Ukai, Subjective evaluation of visual fatigue caused by motion images, Displays 29 (2) (2008) 159166.

63. D. Kim, Y. Jung, E. Kim, Y. Ro, H. Park, Human brain response to visual fatigue caused by stereoscopic depth perception, in: Digital Signal Processing (DSP), 2011 17th International Conference on, no. Ba 19, IEEE, 2011, pp. 1-5.

64. S. Yang, J. E. Sheedy, Effects of vergence and accommodative responses on viewer's comfort in viewing $3 \mathrm{D}$ stimuli, in: Proc. SPIE Stereoscopic Displays and Applications XXII, Vol. 7863, 2011, p. 13.
65. J. Li, M. Barkowsky, P. Le Callet, Visual discomfort is not always proportional to eye blinking rate: exploring some effects of planar and in-depth motion on 3DTV QoE, in: 7th Int. W. on Video Proc. and Quality Metrics, 2013, pp. 1-6.

66. T. Inoue, H. Ohzu, Accommodative responses to stereoscopic three-dimensional display, Applied Optics 36 (19) (1997) 4509.

67. K. Ukai, Y. Kato, The use of video refraction to measure the dynamic properties of the near triad in observers of a 3-D display., J. of the British College of Ophthalmic Opticians (Optometrists) 22 (5) (2002) 385-8.

68. Y. Okada, K. Ukai, J. S. Wolffsohn, B. Gilmartin, A. Iijima, T. Bando, Target spatial frequency determines the response to conflicting defocus- and convergence-driven accommodative stimuli., Vision research 46 (4) (2006) 475-84.

69. M. Torii, Y. Okada, K. Ukai, J. S. Wolffsohn, B. Gilmartin, Dynamic measurement of accommodative responses while viewing stereoscopic images, Journal of Modern Optics 55 (4) (2008) 557-567.

70. T. Fukushima, J. S. Wolffsohn, B. Gilmartin, The relationship between CA / C ratio and individual differences in dynamic accommodative responses while viewing stereoscopic images, Journal of Vision 9 (13) (2009) $1-13$.

71. J. P. Wann, M. Mon-Williams, Health issues with virtual reality displays, ACM SIGGRAPH Computer Graphics 31 (2) (1997) 53-57.

72. T. Shibata, T. Kawai, K. Ohta, M. Otsuki, N. Miyake, Y. Yoshihara, T. Iwasaki, Stereoscopic 3-D display with optical correction for the reduction of the discrepancy between accommodation and convergence, Journal of the Society for Information Display 13 (8) (2005) 665.

73. B. G. Cumming, S. J. Judge, Disparity-induced and blur-induced convergence eye movement and accommodation in the monkey., Journal of neurophysiology 55 (5) (1986) 896-914.

74. S. J. Watt, K. Akeley, A. R. Girshick, M. S. Banks, Achieving near-correct focus cues in a 3-D display using multiple image planes, ACM Transactions on Graphics - Proceedings of ACM SIGGRAPH 200423 (3).

75. Y. Nojiri, H. Yamanoue, A. Hanazato, M. Emoto, F. Okano, Parallax distribution and visual comfort on stereoscopic HDTV, in: Proceedings of SPIE, Vol. 25, SPIE, 2004, pp. 303-313.

76. F. Speranza, W. J. Tam, R. Renaud, N. Hur, Effect of disparity and motion on visual comfort of stereoscopic images, Proc. of SPIE 6055 (2006) 94-103.

77. J. Li, M. Barkowsky, J. Wang, P. Le Callet, Study on visual discomfort induced by stimulus movement at fixed depth on stereoscopic displays using shutter glasses, in: Proceedings of 17th International Conference on Digital Signal Processing, 2011, p. 8.

78. W. Chen, J. Fournier, M. Barkowsky, P. Le Callet, New requirements of subjective video quality assessment methodologies for 3DTV, in: Proc. of 5th Int. Workshop on Video Proc. and Quality Metrics, Vol. 2010, Scottsdale, AZ, USA, 2010.

79. W. N. Charman, H. Whitefoot, Pupil Diameter and the Depth-of-field of the Human Eye as Measured by Laser Speckle, Journal of Modern Optics 24 (12) (1977) 12111216.

80. D. Green, M. Powers, M. S. Banks, Depth of focus, eye size and visual acuity, Vision Research 20 (10) (1980) $827-835$. 
81. A. Cho, T. Iwasaki, K. Noro, A study on visual characteristics of binocular 3-D images, Ergonomics 39 (11) (1996) 1285-1293.

82. S. Marcos, E. Moreno, R. Navarro, The depth-of-field of the human eye from objective and subjective measurements., Vision Res. 39 (12) (1999) 2039-49.

83. I. E. Loewenfeld, The pupil: anatomy, physiology, and clinical applications, 2nd Edition, ButterworthHeinemann, 1999.

84. Z. Li, F. Sun, Pupillary response induced by stereoscopic stimuli., Experimental brain research 160 (3) (2005) 394-7.

85. M. J. Collins, A. Goode, B. A. Davis, A. Back, Spherical aberration and the depth of focus of the human eye, Inv. ophth. \& vis. science 41 (427).

86. Y. K. Nio, N. M. Jansonius, V. Fidler, E. Geraghty, S. Norrby, A. C. Kooijman, Spherical and irregular aberrations are important for the optimal performance of the human eye., J. of the British College of Ophthalmic Opticians 22 (2) (2002) 103-12.

87. F. Yi, Wavefront aberrations and the depth of focus of the human eye, Ph.D. thesis, Queensland University of Technology, Brisbane, Australi (2010).

88. W. Richards, Stereopsis and stereoblindness, Experimental Brain Research 10 (4) (1970) 380-388.

89. G. F. Poggio, B. C. Motter, S. Squatrito, Y. Trotter, Responses of neurons in visual cortex (V1 and V2) of the alert macaque to dynamic random-dot stereograms., Vision research 25 (3) (1985) 397-406.

90. G. F. Poggio, Mechanisms of Stereopsis in Monkey Visual Cortex, Cerebral Cortex 5 (3) (1995) 193-204.

91. B. G. Cumming, G. C. De Angelis, The physiology of stereopsis., Annual review of neuroscience 24 (2001) 203-38.

92. W. Richards, Anomalous Stereoscopic Depth Perception, Journal of the Optical Society of America 61 (3) (1971) 410.

93. K. M. Schreiber, D. B. Tweed, C. M. Schor, The extended horopter: quantifying retinal correspondence across changes of 3D eye position., Journal of vision 6 (1) (2006) 64-74.

94. R. Blake, A Primer on Binocular Rivalry , Including Current Controversies, Brain and Mind 2 (1) (2001) 538.

95. D. Alais, R. Blake, Binocular Rivalry, MIT press, 2004.

96. C. M. Schor, C. W. Tyler, Spatio-temporal properties of Panum's fusional area, Vision Research 21 (5) (1981) 683-692.

97. D. E. Mitchell, A review of the concept of "Panum's fusional area", American journal of optometry 43 (1966) 387-401.

98. D. Fender, B. Julesz, Extension of Panum's Fusional Area in Binocularly Stabilized Vision, Journal of the Optical Society of America 57 (6) (1967) 819.

99. D. R. Hampton, A. E. Kertesz, The extent of Panum's area and the human cortical magnification factor, Perception 12 (2) (1983) 161-165.

100. S. Nagata, The binocular fusion of human vision on stereoscopic displays - field of view and environment effects, Ergonomics 39 (11) (1996) 1273-1284.

101. G. Woo, The effect of exposure time on the foveal size of Panum's area, Vision Research 14 (7) (1974) 473-480.

102. R. Jones, G. L. Stephens, Horizontal fusional amplitudes. Evidence for disparity tuning., Inv. ophthalmology \& visual science 30 (7) (1989) 1638-42.

103. C. M. Schor, I. Wood, J. Ogawa, Binocular sensory fusion is limited by spatial resolution., Vision research 24 (7) (1984) 661-5.
104. W. Van Damme, E. Brenner, The distance used for scaling disparities is the same as the one used for scaling retinal size., Vision Res. 37 (6) (1997) 757-64.

105. K. M. Schreiber, J. M. Hillis, H. R. Filippini, C. M. Schor, M. S. Banks, The surface of the empirical horopter, Journal of Vision 8 (3) (2008) 1-20.

106. E. A. Cooper, J. Burge, The vertical horopter is not adaptable, but it may be adaptive, Journal of Vision 11 (3) (2011) 1-19.

107. P. H. Schiller, N. K. Logothetis, E. R. Charles, Role of the color-opponent and broad-band channels in vision, Vis. Neurosc. 5 (4) (1990) 321-346.

108. M. Livingstone, D. Hubel, Segregation of form, color, movement, and depth: anatomy, physiology, and perception, Science 240 (4853) (1988) 740-749.

109. C. M. Schor, I. Wood, Disparity range for local stereopsis as a function of luminance spatial frequency., Vision research 23 (12) (1983) 1649-54.

110. R. Patterson, Spatiotemporal properties of stereoacuity., Optometry and vision science : official publication of the Am. Ac. of Optometry 67 (2) (1990) 123-8.

111. L. M. Wilcox, R. S. Allison, Coarse-fine dichotomies in human stereopsis., Vision research 49 (22) (2009) 265365 .

112. D. Stransky, L. Wilcox, Depth magnitude and binocular disparity: a closer look at patent vs. qualitative stereopsis, Journal of Vision 10 (7) (2010) 330-330.

113. G. P. Bingham, A. Bradley, M. Bailey, R. Vinner, Accommodation, Occlusion, and Disparity Matching Are Used to Guide Reaching: A Comparison of Actual Versus Virtual Environments, Journal of experimental psychology: human perception and performance 27 (6) (2001) 1314-1334.

114. J. E. Cutting, P. M. Vishton, Perceiving layout and knowing distances : The integration, relative potency, and contextual use of different information about depth, Handbook of perception and cognition 5 (1995) 69-117.

115. Y. Li, T. Sawada, Y. Shi, T. Kwon, Z. Pizlo, A Bayesian model of binocular perception of 3D mirror symmetrical polyhedra, J. of Vision 11 (4) (2011) 1-20.

116. R. T. Held, E. A. Cooper, J. F. O'Brien, M. S. Banks, Using blur to affect perceived distance and size, ACM Transactions on Graphics 29 (2) (2010) 1-16.

117. M. S. Landy, L. T. Maloney, E. B. Johnston, M. Young, Measurement and modeling of depth cue combination: in defense of weak fusion., Vision research 35 (3) (1995) 389-412.

118. F. Domini, C. Caudek, H. Tassinari, Stereo and motion information are not independently processed by the visual system., Vision Res. 46 (11) (2006) 1707-23.

119. H. Ono, T. Comerford, Stereoscopic depth constancy, in: W. Epstein (Ed.), Stability and constancy in visual perception: mechanisms and processes, Wiley, New York, 1977, pp. 91-128.

120. S. Nakamizo, The Pulfrich effect and depth constancy, Japanese Psychological Research 42 (4) (2000) 251-256.

121. W. Richards, Configuration stereopsis: a new look at the depth-disparity relation., Spatial vision 22 (1) (2009) 91-103.

122. S. Shimojo, K. Nakayama, Real world occlusion constraints and binocular rivalry, Vision Research 30 (1) (1990) 69-80.

123. J. M. Wolfe, Stereopsis and binocular rivalry., Psychological review 93 (3) (1986) 269-82.

124. W.-J. Kim, Feature-Based Detection of Inverted-Stereo for Stereoscopic 3D Viewing Comfort, IEEE Trans. on Broadcasting 58 (2) (2012) 296-300. 
125. B. Mendiburu, 3D movie making: stereoscopic digital cinema from script to screen, Focal Press, 2009.

126. L. Onural, T. Sikora, J. Ostermann, An assessment of 3D-TV technologies, in: Proceedings of National Association of Broadcasters, 2006, pp. 456-467.

127. R. Patterson, A. Silzars, Immersive stereo displays, intuitive reasoning, and cognitive engineering, J. Society for Inf. Display 17 (5) (2009) 443-448.

128. A. S. Percival, The relation of convergence to accommodation and its practical bearing, Ophthalmo- logical Review 11 (1892) 313-328.

129. C. Sheard, The prescription of prisms, Am. Journ. of Optometry 11 (1934) 364-378.

130. G. Cermak, L. Thorpe, M. Pinson, Plan for Evaluation of Video Quality Models for Use with High Definition TV Content. Video Quality Experts Group (VQEG)., Tech. rep. (2009).

131. ITU-R BT.2022, General viewing conditions for subjective assessment of quality of SDTV and HDTV television pictures on flat panel displays BT Series Broadcasting service, Tech. rep. (2012).

132. R. S. Allison, Analysis of the Influence of Vertical Disparities Arising in Toed-in Stereoscopic Cameras, J. of Imaging Science and Tech. 51 (4) (2007) 317.

133. F. Speranza, L. M. Wilcox, Viewing stereoscopic images comfortably: the effects of whole-field vertical disparity, Proc. SPIE Stereoscopic displays and virtual reality systems 4660 (2002) 18-25.

134. F. Kooi, A. Toet, Visual comfort of binocular and 3D displays, Displays 25 (2-3) (2004) 99-108.

135. L. B. Stelmach, W. J. Tam, F. Speranza, R. Renaud, T. Martin, Improving the visual comfort of stereoscopic images, SPIE, 2003.

136. J. Carreira, L. Pinto, N. Rodrigues, S. Faria, P. Assuncao, Subjective assessment of frame loss concealment methods in $3 \mathrm{D}$ video, in: 28th Picture Coding Symposium, IEEE, 2010, pp. 182-185.

137. M. Slanina, T. Kratochvíl, V. íčný, Testing QoE in Different 3D HDTV Technologies, Radioengineering 21 (1) (2012) 445-454.

138. S.-n. Yang, J. Sheedy, J. R. Hayes, Comparison of Visual Experiences and Display Preference in Viewing Stereoscopic 3D TV with Optically-corrected Active Shutter and Film Pattern Retarding Glasses, Tech. rep., Faculty Scholarship (COO) (2011).

139. A. Woods, Understanding crosstalk in stereoscopic displays, Three-Dimensional Systems and Applications (2010) 11.

140. I. Tsirlin, L. M. Wilcox, R. S. Allison, The Effect of Crosstalk on the Perceived Depth From Disparity and Monocular Occlusions, IEEE Transactions on broadcasting 57 (2) (2011) 445-453.

141. Y. Y. Yeh, L. D. Silverstein, Limits of fusion and depth judgment in stereoscopic color displays., Human factors 32 (1) (1990) 45-60.

142. M. Siegel, Perceptions of crosstalk and the possibility of a zoneless autostereoscopic display, in: Proceedings of SPIE, SPIE, 2001, pp. 34-41.

143. W. J. Tam, L. Zhang, 3D-TV content generation: 2Dto-3D conversion, in: IEEE International Conference on Multimedia and Expo, 2006, pp. 1869-1872.

144. L. Zhang, C. Vázquez, S. Knorr, 3D-TV Content Creation : Automatic 2D-to-3D Video Conversion, IEEE Trans. on broadcasting 57 (2) (2011) 372-383

145. J.-H. Choi, M.-J. Yun, A.-R. Kim, J.-O. Kim, Visual comfort measurement for $2 \mathrm{D} / 3 \mathrm{D}$ converted stereo video sequence, in: 3DTV-Conference, IEEE, 2012, pp. 1-4.
146. G. Mather, D. R. Smith, Depth cue integration: stereopsis and image blur., Vision research 40 (25) (2000) 3501-6.

147. J. Wang, M. Barkowsky, V. Ricordel, Quantifying how the combination of blur and disparity affects the perceived depth, SPIE Electronic Imaging 7865 (2011) 110 .

148. Q. Huynh-Thu, M. Barkowsky, P. L. Callet, The Importance of Visual Attention in Improving the 3D-TV Viewing Experience : Overview and New Perspectives, IEEE Transactions on broadcasting 57 (2) (2011) 432444.

149. K. N. Ogle, T. J. Schwartz, Depth of Focus of the Human Eye, Journal of the Optical Society of America 49 (3) (1959) 273.

150. Y. Zhang, G. Jiang, M. Yu, K. Chen, Stereoscopic visual attention model for $3 \mathrm{~d}$ video, in: 16th Int. Conf. on Advances in Multimedia Modeling, 2010, pp. 314-324.

151. H. Sohn, Y. J. Jung, S.-i. Lee, H. W. Park, Y. M. Ro, Attention model-based visual comfort assessment for stereoscopic depth perception, in: 2011 17th International Conference on Digital Signal Processing (DSP), IEEE, 2011, pp. 1-6.

152. S.-i. Lee, Y. J. Jung, H. Sohn, Y. M. Ro, H. W. Park, Visual discomfort induced by fast salient object motion in stereoscopic video, Proc. of SPIE 7863.

153. S. J. Daly, R. T. Held, D. M. Hoffman, Perceptual Issues in Stereoscopic Signal Processing, IEEE Transactions on broadcasting 57 (2) (2011) 347-361.

154. K. Murata, S. Araki, K. Yokoyama, K. Yamashita, T. Okumatsu, S. Sakou, Accumulation of VDT workrelated visual fatigue assessed by visual evoked potential, near point distance and critical flicker fusion., Industrial health 34 (2) (1996) 61-9.

155. Y. Suzuki, Y. Onda, S. Katada, S. Ino, T. Ifukube, Effects of an eyeglass-free 3-D display on the human visual system., Jap. jour. of ophth. 48 (1) (2004) 1-6.

156. J. Choi, D. Kim, B. Ham, S. Choi, K. Sohn, Visual fatigue evaluation and enhancement for 2D-plus-depth video, in: 17th IEEE Int. Conf. on Image Proc., IEEE, 2010, pp. 2981-2984. 